\title{
FEASIBILITY STUDY OF RAP AS AGGREGATES IN CEMENT CONCRETE
}

\author{
Manjunatha K A ${ }^{1}$, Narasimha murty $\mathbf{M ~ R}^{2}$, Murali Mohan $\mathrm{M} \mathrm{V}^{\mathbf{3}}$, Antony Sebastian ${ }^{4}$ \\ ${ }^{1}$ Assistant Professor, SJC institute of Technology, Visvesvaraya Technological University, Karnataka, India \\ ${ }^{2}$ Student, SJC institute of Technology, Visvesvaraya Technological University, Karnataka, India \\ ${ }^{3}$ Student, SJC institute of Technology, Visvesvaraya Technological University, Karnataka, India \\ ${ }^{4}$ Student, SJC institute of Technology, Visvesvaraya Technological University, Karnataka, India
}

\begin{abstract}
Concrete is the basic material in all construction works and coarse aggregates constitute more than $50 \%$ of the mix. But the procurement and generation of natural aggregates is getting difficult day by day because of lack of natural source and environmental effects. In search of alternative for natural aggregates, lead to the usage of Reclaimed Asphalt Pavement aggregates, which are produced abundantly due to replacement of Flexible Pavements with Rigid Pavements in India. This study is taken up to determine the variation of different properties of strength and flexural strength of concrete with natural aggregates and RAP aggregates. The cubes will be casted and tested for Strength and Flexural Strength is also determined by casting beams. The results can be analyzed to identify the importance of RAP aggregates for its effective and efficient usage for present scenario of India. The RAP Aggregates are procured from Kanmangla flyover, Bangalore. And it is checked for the effective utilization in Concrete. RAP aggregates are replaced with Natural Aggregates by $50 \%$ and $25 \%$ and evaluated.
\end{abstract}

Keywords: concrete, flexural strength, compressive strength, reclaimed asphalt pavement (RAP).

\section{INTRODUCTION}

Concrete is most widely used construction material in the world. Because of its ability to get cast in any form and shape, it has almost replaced old construction materials such as brick and stone masonry. The strength and durability of concrete can be changed by making appropriate changes in its ingredients like cementitious material, aggregate and water and by adding some special ingredients. Hence concrete is very well suited for a wide range of applications. However concrete has some deficiencies as listed below, Low tensile strength, Low post cracking capacity, Brittleness and low ductility, Limited fatigue life, not capable of accommodating large deformations, Low impact strength. The highway construction industry has made rapid strides in the field of innovative technologies up-gradation and adaption. With increasing traffic volumes and an increased demand for innovative rehabilitation and repair of the aging transportation infrastructure, there is scope for new concepts that prove to be viable and cost effective solution for pavement rehabilitation. Newer materials have been tried with a lot of emphasis on optimizing life cycle cost and minimizing the pavement distresses. Each year, the highway industry produces over several million tons of reclaimed asphalt pavements (RAP) through the rehabilitation and construction of the nation's roads. Although this product has been reused in several applications, usually in hot plant mixes, a large portion of this material remains unused. With a sizeable share of RAP wasted in stockpiles and landfills, the exploration of further uses for this construction by product is warranted. Using RAP as aggregate in Ordinary Portland cement concrete (OPCC) is one attractive application for a further use of this recyclable material.
Earlier research has demonstrated the feasibility of creating concrete with RAP aggregate; however, prior studies focus on mechanical properties of the material. This project work encompasses the development of RAP in OPCC mixtures that will subsequently move forward for a more thorough evaluation of their material properties. The mixing experiment and preliminary testing phases of this project provided information to draw a number of conclusions about the appropriateness of RAP aggregate in OPCC. Portions of virgin aggregate used to produce concrete pavement may be replaced with RAP, creating a pavement that is both efficient and environmentally friendly.

Concrete does the basic material in all construction works and coarse aggregates constitute more than $50 \%$ of the mix. But the procurement and generation of natural aggregates is getting difficult day by day because of lack of natural source and environmental effects. In search of alternative for natural aggregates, lead to the usage of Reclaimed Asphalt Pavement aggregates, which are produced abundantly due to replacement of Flexible Pavements with Rigid Pavements in India. This study is taken up to determine the variation of different properties of strength of concrete pavements with natural aggregates and RAP aggregates. The cubes will be casted and tested for Strength and Flexural Strength is also determined by casting beams. The results can be analysed to identify the importance of RAP aggregates for its effective and efficient usage for present scenario of India. RAP aggregates are replaced with Natural Aggregates by $50 \%$ and $25 \%$ and evaluated. 


\section{LITERATURE SURVEY}

[1]Delwar, Fahmy, and Taha of the University of Washington and Sultan QaboosUniversity performed one of the first studies on this "green" concrete in 1997. The main goals of their research entailed an investigation on the feasibility of using RAP as aggregate in Portland cement concrete (PCC), and the determination of key material properties and characteristics of the alternative material. RAP millings for use in the concrete test mixtures were obtained from an asphalt producer in Spokane, Washington. The research team processed the material through a set of sieves, removing any aggregate larger than $3 / 4$-inch and fractionating the material on the No. 4 sieve. Standard concrete sand and gravel, as well as type I/II cement were purchased from a company in Moscow, Idaho for use in the study. Mixes containing 10 different aggregate arrangements with two different water-cement (w/c) ratios were tested for compressive strength and stress-strain characteristics. Data on the slump, air content, and unit weight of the wet concrete were also recorded.

[2]Huang, Shu, and Li of the University of Tennessee and Louisiana State University expanded the available information on concrete containing RAP with their work in 2005.The objective of their study was to further research the effect of the inclusion of RAP aggregates on the toughness and brittle failure behavior of Portland cement concrete. The study hypothesized that the fine layer of asphalt coating the individual pieces of aggregate protects the particles from breakage and facilitates the increased dissipation of energy in the event of a crack.

[3]Huang \&Shu, After Huang and Shu's initial research on RAP concrete, they performed additional testing on specimens that included admixtures to help improve the performance of the material (Huang, Shu, \& Li, 2005). Both silica fume and a high-range water reducing agent (HRWRA) were added to help reduce the loss of strength accrued by the use of the RAP aggregate. As in prior studies, several mix designs using different percentages of coarse and/or fine RAP aggregate (10, 30, 50, or 100 percent by weight) were used as a replacement for virgin aggregate.

[4]Hossiney, In 2008, Nabil Hossiney from the University of Florida worked with the Florida Department of Transportation (FDOT) to study the performance of RAP concrete used in a rigid pavement application. In their study, four concrete mixtures containing reclaimed asphalt pavement were evaluated in a laboratory setting. The tested material properties were then used to create a finite element model to assess how the concretes would behave as a pavement under typical Florida roadway conditions. The natural aggregate for the mixing experiment consisted of a porous limestone coarse rock and a standard silica sand fine material. The mixtures evaluated in the study included mix designs containing $0,10,20$, and 40 percent RAP aggregate. Laboratory test results indicated that the compressive strength, splitting tensile strength, flexural strength, and elastic modulus of the hardened material were inversely related to the amount of RAP in the mix; these material properties all decreased as the RAP replacement rate was increased.

\section{PRESENT INVESTIGATIONS}

The physical properties of materials used in the experiments are determined with the standard test procedures as per Indian Standard (IS) Codes. Test results are tabulated as given below.

Table 3.1 properties of cement

\begin{tabular}{|l|l|l|}
\hline Sl.No. & Characteristics & Results \\
\hline $\mathbf{1 .}$ & $\begin{array}{l}\text { Normal consistency( } \\
\%)\end{array}$ & $32 \%$ \\
\hline $\mathbf{2 .}$ & $\begin{array}{l}\text { Initial setting } \\
\text { time(minutes) }\end{array}$ & 34 \\
\hline $\mathbf{3 .}$ & $\begin{array}{l}\text { Final setting } \\
\text { time(minutes) }\end{array}$ & $\begin{array}{l}\text { Not more than 600 } \\
\text { minutes as per IS code } \\
\text { 4031 part 5 }\end{array}$ \\
\hline $\mathbf{4 .}$ & Specific gravity & 3.04 \\
\hline
\end{tabular}

Table 3.2 properties of $\mathrm{M}$ sand

\begin{tabular}{|l|l|l|}
\hline SL.No & Characteristics & Value \\
\hline 1. & Specific gravity & 2.41 \\
\hline 2. & Water absorption & $4.6 \%$ \\
\hline 3. & Grading Zone & Zone II \\
\hline
\end{tabular}

Table 3.3Properties of Coarse aggregates

\begin{tabular}{|l|l|l|}
\hline SL.No & Test Name & Results \\
\hline 1. & Specific gravity & 2.62 \\
\hline 2. & Water absorption & $0.33 \%$ \\
\hline 3. & Crushing value & $24.2 \%$ \\
\hline 4. & Impact value & $22.2 \%$ \\
\hline
\end{tabular}

Table 3.4 Properties For Different \% Replacement of RAP with Natural Aggregates

\begin{tabular}{|l|l|l|l|}
\hline SL.No. & Characteristics & $\begin{array}{l}\mathbf{2 5 \%} \\
\text { RAP }\end{array}$ & 50\% RAP \\
\hline $\mathbf{1 .}$ & Specific gravity & 2.54 & 2.44 \\
\hline $\mathbf{2 .}$ & Water absorption & $0.77 \%$ & $0.1 \%$ \\
\hline
\end{tabular}

Based on these material properties, the Mix Design is prepared for Normal Concrete Mix (NC), Mix 1 (100\% RAP), Mix 2 (75\% RAP), are obtained as follows,

Table 3.5 Mix Proportions

\begin{tabular}{|l|l|}
\hline Mix & $\begin{array}{l}\text { Cement:FA:RAP:Natural } \\
\text { aggregates:water }\end{array}$ \\
\hline NC (Normal Mix) & $1: 2.18: 0: 3.02: 0.45$ \\
\hline $\begin{array}{l}\text { Mix-1 } \\
(25 \% \text { RAP) }\end{array}$ & $1: 2.18: 0.73: 2.26: 0.45$ \\
\hline $\begin{array}{l}\text { Mix-2 } \\
(50 \% \text { RAP) }\end{array}$ & $1: 2.18: 1.4: 1.5: 0.45$ \\
\hline
\end{tabular}


Cube and beam specimen are cast as per IS: 516-1978. In this process, once the wet concrete mixture is prepared of required standard the concrete is filled in cube moulds $(150 \times 150 \times 150 \mathrm{~mm})$ for compressive strength test. For flexural strength the prisms $(700 \mathrm{X} 150 \mathrm{X} 150 \mathrm{~mm})$ were casted. The specimen are removed after 24 hours and immersed in water tank for 3, 7, 14 and 28 days. Then the specimen were removed from curing tank and tested immediately under Compression Testing Machine / Flexural Testing Machine.

\section{RESULTS AND DISCUSSIONS}

\subsection{Compressive Strength}

The cube specimens were tested in Compression Testing Machine (CTM) after specified curing period for different percent of RAP replacement $25 \%, 50 \%$, and for normal concrete mix (NC). The compressive strengths after respective curing periods are noted in Table 4.1

Table 4.1 Compressive Strength Results

\begin{tabular}{|l|l|l|l|l|}
\hline \multirow{2}{*}{ Composition } & \multicolumn{3}{|l}{ Compressive } \\
N/mm2 & \multicolumn{3}{l|}{ Strength in } \\
\cline { 2 - 5 } & 3 day & 7 day & $\begin{array}{l}14 \\
\text { day }\end{array}$ & 28 day \\
\hline NC & 21.216 & 25.87 & 34.58 & 38.077 \\
\hline $25 \%$ RAP & 19.76 & 19.03 & 23.25 & 32.26 \\
\hline $50 \%$ RAP & 15.84 & 19.47 & 21.50 & 27.32 \\
\hline
\end{tabular}

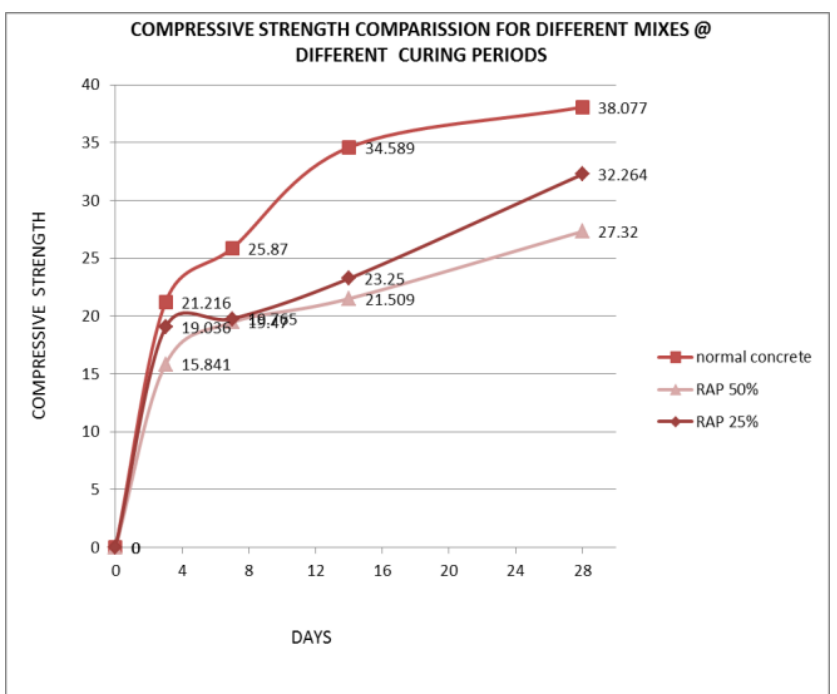

Fig 4.1 Graph showing Compressive Strength Development of Different Mixes

Mix 1 is giving maximum strength of $85 \%$ of NC strength, $32.26 \mathrm{~N} / \mathrm{mm}^{2}$ which is very nearer to Normal Concrete Mix Strength for 28 days curing period. And also Mix 1 is showing good early strength of $19.76 \mathrm{~N} / \mathrm{mm}^{2}$ for 3 day curing period.

\subsection{Flexural Strength}

The specimens were tested in flexural testing machine and the flexural strength is calculated depending on the failure plane position from the supports. Values obtained for concrete with different RAP replacement levels and for the normal concrete mix (NC) are as note in Table 4.2

Table 4.2 Flexural Strength Results

\begin{tabular}{|l|l|l|l|l|}
\hline \multirow{2}{*}{ Composition } & \multicolumn{4}{|l|}{ Compressive Strength in N/mm2 } \\
\cline { 2 - 5 } & 3 day & 7 day & 14 day & 28 day \\
\hline NC & 4.24 & 4.78 & 5.8 & 6.23 \\
\hline $25 \%$ RAP & 4.22 & 4.56 & 5.36 & 6.16 \\
\hline $50 \%$ RAP & 4.10 & 4.22 & 5.31 & 5.86 \\
\hline
\end{tabular}

\section{FLEXURAL STRENGTH COMPARISION FOR DIFFERENT MIXES} @DIFFERENT CURING PERIODS

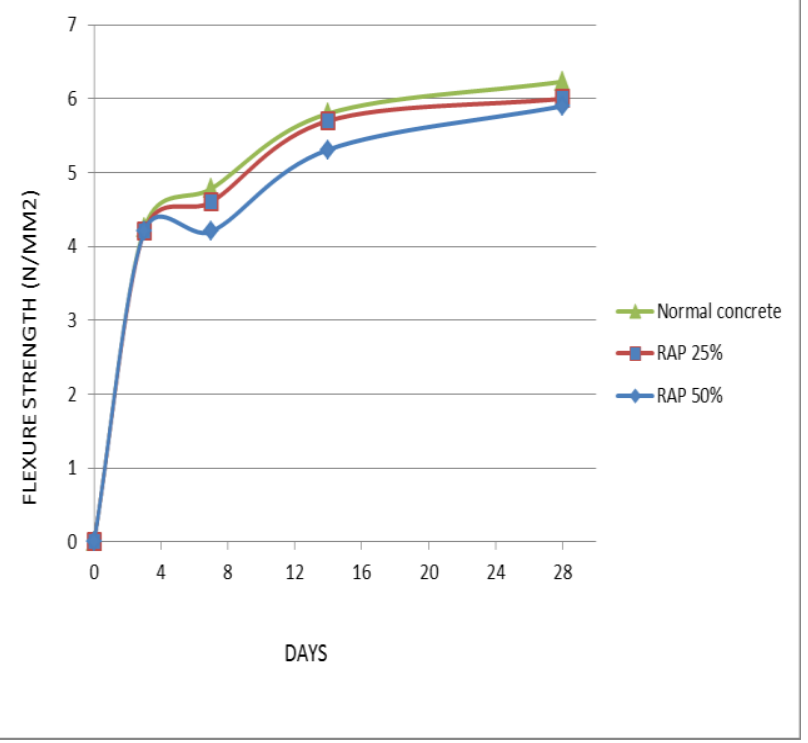

Fig 4.2 Graph showing Flexural Strength Development of Different Mixes

\subsection{Discussions on Flexural Strength Results}

From the test results of flexural strength, it is observed that NC shows higher flexural strength compared to different RAP replacement levels. Mix 1 shows higher flexural strength of $6.16 \mathrm{~N} / \mathrm{mm}^{2}$ for 28 days curing period, which is very nearer ( $98.8 \%$ of NC Strength) to strength of Normal Concrete $\left(6.23 \mathrm{~N} / \mathrm{mm}^{2}\right)$.

\section{CONCLUSION}

Replacement of 25\% RAP (Mix-1) gives maximum compressive strength comparatively less than other replacement percentages (About $85 \%$ of NC Strength).

$\checkmark \quad$ Increase in RAP content decreases the compressive strength, and with the use of $25 \%$ RAP 28 days compressive strength of $32.26 \mathrm{Mpa}$ was obtained which was more than mean compressive strength (30Mpa). Hence using 25\% RAP can be used in normal concrete.

$\checkmark \quad$ Normal mix shows maximum flexural strength more than the RAP replaced mixes. But the Mix-1, i.e. $25 \%$ RAP replacement is giving strength very nearer to that of NC. 
The supporting factors to justify the use of RAP Mix are:

- $\quad$ Easy to remove flexible pavement and use its material for placing of concrete pavement. Thus reducing transportation cost and cost of natural aggregates.

- Use of RAP aggregate also reduces the burden on natural course aggregate for increasing aggregate demand for construction of roads.

- It helps to reduce environmental imbalances and pollution while removing natural aggregate in quarry.

\section{REFERENCES}

[1] International Journal of scientific research and management

||Volume ||2||Issue||8||Pages |1271

1278 |2014||Website: www.ijsrm.in ISSN (e): 23213418

[2] Delwar, M., Fahmy, M., \&Taha, R. (1997), Use of Reclaimed Asphalt Pavement as an Aggregatein Portland Cement Concrete. ACI Materials Journal (May - June 1997), 251-256.

[3] Huang, B., Shu, X., \& Li, G. (2005), Laboratory Investigation of Portland Cement Concrete Containing Recycled Asphalt Pavements. Cement and Concrete Research , 2008-2013.

[4] Huang, B., \&Shu, X. (2005),Experimental Study on Properties of Portland Cement Concrete Containing Recycled Asphalt Pavements. Innovations for Concrete Pavement: Technology Transfer for the Next Generation (pp. 485-499). Colorado Springs: International Society for Concrete Pavements.

[5] Hossiney, N. J. (2008), Evaluation of Concrete Containing RAP for use in Concrete Pavement,Civil Engineering, Gainesville: University of Florida.

[6] Concrete Technology (Theory and Practices) by M.S. SHETTY. S.Chand\& Company Pvt.LtdPublications.

[7] Highway Engineering by S.K.Khanna and C.E.G.Justo, Nem Chand \& Bros, Roorkee,U.K.,India (Ninth Edition 2011).

[8] Principles and Practices of Highway Engineering - by Dr. L R Kadyali, Dr. N B Lal.

[9] IRC: 15-2011, Standard Specifications and code of practice for Construction ofConcrete Roads, $4^{\text {th }}$ Revision, Indian Roads Congress, New Delhi.

[10] IRC: 44-2011, Guidelines for cement concrete mix design for pavements, IndianRoads Congress, New Delhi.

[11] IS: 10262-2009, Indian Standard CONCRETE MIX PROPORTIONING -GUIDELINE (First Revision). 